
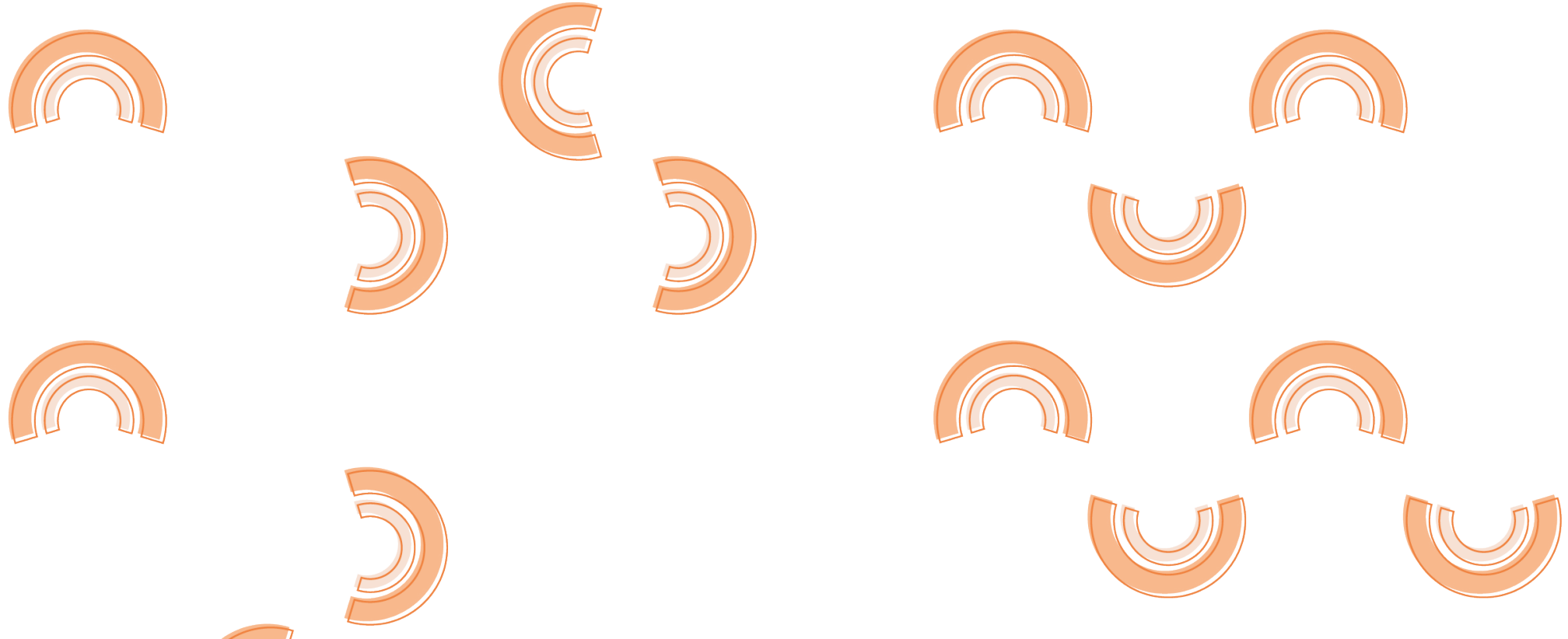

\title{
HUGUIANAS
}

\section{ENTREvista Hugo RodAS ${ }^{1}$}

Universidade de Brasília. 
MARIANA Obrigada primeiramente por estar disponibilizando esse espaço para a gente. Nós fazemos a disciplina de Poética Teatrais, com o professor Marcus e somos todos do Primeiro Semestre de Artes Cênicas. Então, nós queríamos fazer algumas perguntas pra você. Muitos de nós estamos começando na área por agora, e nós gostaríamos de saber se você poderia compartilhar um pouco com a gente sobre o início da sua carreira, seu primeiro contato com teatro, seus interesses, suas certezas, incertezas...

HUCO Bom, meu primeiro contato com arte, que é um pouco mais importante que o primeiro contato com o teatro, foi a música. Por uma educação particular que deram meus pais na pequena cidade de Juan Lacaze onde nasci, estudava desenho, pintura, idiomas, piano (dos seis anos aos dezoito); eu sou professor de piano e solfejo ${ }^{2}$. Meu grande primeiro título foi de 'professor de piano e solfejo'. Acho que a música e o desenho são duas coisas extremamente importantes dentro do meu trabalho. Depois, quando eu me mudei para Montevidéu para estudar na faculdade, foi aí que eu comecei com a minha verdadeira vocação - comecei a fazer dança, entrei num curso de teatro, e aí a vida foi trocando e todas as coisas começaram a ter um sentido para mim, ajuntarem-se dentro de mim...

MARIANA E pintura e música quando você era bem pequeno, não é? HUCO Sim, sim... Dos seis anos até os...

MARIANA Você estudou em casa?

HUCO Sim, eu estudei em casa, não fui à escola... Talvez se eu tivesse socializado desde pequeno talvez eu tivesse sido um pouco melhor... (risos)
1 N.E. Entrevista realizada a partir da disciplina Poéticas Teatrais, ministrada por Marcus Mota, no segundo semestre de 2017. A entrevista foi conduzida pelos alunos Mariana Borges, Mariana Borges da Fonseca, Catarina Kirst Costa de Medeiros, Felipe Alessandro Laya Zordan, João Victor Alvino Cury e Ana July Cabral Oliveira, todos do curso de Bacharelado em Artes Cênicas da Universidade de Brasília. Durante a disciplina, os alunos foram divididos em grupos de pesquisa, cada grupo com um tema de pesquisa. Uma das metodologias foi a de entrevistas semi-estruturadas, aqui apresentada.

2 N.E. Mais sobre este tópico de formação artística e existencial de Hugo Rodas, V. a dissertação de mestrado de Claudia Moreira de Souza O garoto de Juan Lacaze: Invenção no teatro de Hugo Rodas (Universidade de Brasília, 2007). Link: http:// repositorio.unb.br/handle/10482/3299?mode=full 
MARIANA E aí com o teatro mesmo foi quando você se mudou para Montevidéu? HUGO Não, quando me mudei para Montevidéu a faculdade foi se distanciando, e comecei, como já falei, a traçar meu próprio caminho, comecei a fazer dança, entrei num curso de teatro, uma escola dos anos 60, totalmente 'grotowiskiana', e toda aquela educação começou a ter vida e a vida a ser teatro, o "teatro físico". Foi marcante a junção da dança com o teatro - o gesto, ele começou a ter uma importância maior que a palavra nessa época, pois a ditadura censurava fortemente, os textos eram absolutamente massacrados e um braço levantado, um chute no ar, uma luta no vazio, uma lata de tinta vermelha derramada, para eles não significava nenhum perigo... Isso foi transformando e delineando uma linguagem. E, no final de 1969, formamos o primeiro grupo de dança teatro falando de nossas vidas, de nossos sonhos, de nossa alegria, de nosso desespero, e continuamos assim até hoje.

MARIANA E, olhando um pouco para essa sua trajetória artística, para os prêmios, as conquistas, de que aspectos você mais se orgulha e quais foram os principais obstáculos que você encontrou para exercer a sua arte?

HUGO Quais são os aspectos que mais me orgulham? Não sei... eu acho que um dos meus maiores orgulhos foi ter ficado aqui, de sentir-me um pioneiro, de ter sentido a importância de iniciar um trabalho junto a uma cidade que nascia ao mesmo tempo.

MARIANA Em Brasília que você diz, não é?

HUGO Sim, sim aqui em Brasília, onde comecei realmente a sentir que tinha os materiais necessários para entrar em um trabalho, para poder passar um trabalho e não o simples fato de executar algo em função de mim. Foi incrível, um espaço ideal, tão ideal que eu costumo dizer que eu não escolhi Brasília, Brasília me escolheu: eu vim aqui dar um curso de 15 dias, e, quando eu ia embora, as pessoas perguntaram o que que eu precisava para ficar aqui, e eu disse: "Bom, eu sou livre, então um lugar para trabalhar e gente para trabalhar"... E me disseram: "Bom, aqui tem uma lista com 50 alunos e você vai trabalhar no Clube do Congresso", onde existia um clube de cinema, e seu diretor formalizou meu contrato e assim foi que tudo começou...

MARIANA E quais foram os principais obstáculos que você identifica, olhando para esse caminho que você enfrentou?

HUCO É difícil... Eu nunca enfrentei muitos obstáculos, eu faço deles uma coisa normal: na minha vida, um obstáculo não é um obstáculo, é uma provocação para você seguir em frente. Eu não sinto a coisa como algo que vem e me freia. Eu tra-
3 N.E. Hugo refere-se às propostas de Jerzy Crotowski. V. do autor Em busca de um teatro pobre (Civilização Brasileira, 1971) e Teatro Laboratório de Jerzy Grotowski (Perspectiva, 2007). 
balho e passo por cima, vou em frente com isso, não é algo que me detém, não é algo que eu tenha que superar. Talvez hoje em dia essa palavra seja um pouco mais importante, por que todos nós hoje em dia tentamos sobreviver do teatro... Coisa absolutamente razoável, já que é nossa profissão, mas muito difícil em qualquer cidade, ainda mais em Brasília... Eu sobrevivo como professor e me sinto muito feliz com isso, por que assim posso não ficar dependente do sucesso. Ter um êxito rentável como Os Saltimbancos, em 1976, com o grupo Pitu, que levou um público naquela época de 700 pessoas todas as noites no teatro Galpão e, logo, em quase todas as salas da cidade, escolas, parques, inclusive no Ginásio Nilson Nelson para 20.000 alunos das escolas, é algo inesquecível e único! Fazer de uma peça infantil um sucesso de adultos só foi possível por que a gente trabalhava dentro daqueles animais (da peça) quem éramos e como nos sentíamos dentro da sociedade nesse momento, que também era como se sentia todo o mundo. Foi uma coisa que nos abriu portas para fora da cidade, um impacto muito grande aqui (Brasília) e no Brasil. Em 1977, ganhamos nosso primeiro reconhecimento com o prêmio concedido pelo Serviço Nacional do Teatro e, junto com o Trabalho Número 2 e vários outros, por muitos anos percorremos da oficina de dança da Bahia até os festivais de inverno do Ouro Preto... Para conseguir algo parecido tivemos que esperar quase 30 anos: com o Adubo voltamos a percorrer o país até hoje: onze anos, assim como o Ensaio Geral que já tem 6 anos de vida. Três casos em 42 anos! Dá pra ser feliz, mas não para sobreviver...

MARIANA Existe alguma particularidade em relação aos artistas de Brasília comparado a outros lugares que você trabalhou, você identifica alguma particularidade?

HUGO É divertido, por que todo mundo considera que eu sou uma das coisas mais velhas de Brasília (risos); então, isso é muito divertido, por que a quantidade de gente que tenho formado nesse espaço me leva a me sentir no paraíso cheio de pessoas que me entendem e entendem meu trabalho e que eu entendo o trabalho que estão fazendo, certo?! Então, creio que realmente por isso fiquei! Creio que por algo existo nessa cidade e sou quem sou nessa cidade. Eu me dediquei a essa cidade e a cidade me retribuiu de uma maneira fantástica com vocês!

MARIANA E, aproveitando o gancho, nós queríamos saber um pouco da sua percepção a respeito dos jovens intérpretes atualmente e se existe alguma diferença, por que como você mesmo disse "sou uma das coisas mais velhas de Brasília”, você formou muita gente... Então você percebe alguma diferença entre os jovens intérpretes dos anos $80,90,2000 . . . ?$ 
HUGO É difícil, por que eu sinto que, de repente, entrou uma orientação que interpreta mal a palavra 'performance'. Valoriza-se demais a "autoestima": "eu sou assim e é assim que devo ser", e "é assim que faço 'teatro". Acho que isso tem dificultado um pouco o entendimento do que é ser um ator, da técnica necessária para me transformar em um instrumento capaz de interpretar absolutamente qualquer papel, de ter a fome e dedicação para procurar fora de uma formação as diferentes técnicas que permitam o enriquecimento da mesma e não essa autoconfiança excessiva em você mesmo, e ficar nisso e por isso mesmo... Eu sinto que, de repente, formamos elencos em função da característica do ator, rotulando assim o trabalho dele sem permitir a possibilidade de outras experiências tanto a ele, quanto a você mesmo em seu papel de orientador. No começo, como ator, eu vivi muito isso. Daí o meu terror de engavetar e ser engavetado. Detesto que te cataloguem e, para isso, não ocorrer, devemos trabalhar para não permitir que nos ponham adjetivos que limitem a nossa ação.

MARIANA E que gaveta seria essa?

HUGO Por exemplo: no Beirute você tinha uma mesa como os melhores jornalistas do Brasil, outra mesa com os artistas plásticos, outra com os músicos, outra cheia de malucos. Você corria de mesa em mesa e a informação era brutal, você podia até fechar uma produção em uma noite . Agora você vai ao bar dos intelectuais, ao bar dos ricos, ao bar dos pobres, entendeu? Tudo ficou demasiadamente engavetado. É como uma espécie de segregação. Eu detestei sempre que me catalogassem como gordo, homossexual, drogado. Eu luto contra isso, contra que alguém me marque e diga que sou tal coisa. Eu sou um ser humano livre capaz de amar e de viver e de ser apaixonado pelo o que bem "me dá na tecla" e não tenho que provar isso para ninguém. Lutei a vida inteira para ter essa liberdade sexual e de crença que hoje temos, e, ao que parece, podemos perder a qualquer momento. É difícil entender, às vezes, por que as palavras podem ser interpretadas ao contrário... Estou em prol desta liberdade, que me permite não ter medo, não ter que me cuidar do outro, por que ocupo um lugar e esse lugar está certo. Os personagens, me pergunto se às vezes se eles não formam parte de um grande espetáculo nos corredores e não nas salas de aula... É uma coisa inacreditável, mas estamos trabalhando com personagens que criamos como arma de defesa, coisa que atrasa qualquer processo, por que você tem que destruí-los para poder chegar ao centro. $E$ isso é muito cruel por que é terapêutico demais. Temos que acabar com as nossas afetações para poder entrar no trabalho limpos, para poder começar do zero. É perigoso quando não existe diálogo, quando simplesmente defen-
4 N.E. Bar histórico de Brasília. V. o livro de depoimentos organizado por Fernando Fonseca Beirute. Bar que inventamos (Ideal, 2010). 
demos posições. É difícil entender isso dos personagens por que, às vezes, acreditamos que somos eles e não nós mesmos... Semestre passado trabalhamos 'gêneros' para tentar recuperar o feminino e o masculino de cada um de nós e não aquilo que imaginamos ser, não o estereótipo dos gêneros, os "personagens" dos gêneros, "personagens trabalhando personagens"... E sim nossa própria mulher, nosso próprio homem... Foi demais para todos ${ }^{5}$.

MARIANA Você e o professor Marcus têm trabalhado com jovens universitários na montagem de óperas e musicais há algum tempo e, atualmente, o Salomônicas ${ }^{6}$. Como que tem sido essa parceria com o Marcus ${ }^{7}$ ? HUCO Bom, Marcus é uma pessoa que tem me ajudado a vida inteira... É uma pessoa que acredita muito no trabalho. Somos duas pessoas bastante difíceis, mas em trabalho somos muito unidos, acreditamos muito um no outro e nos ajudamos muito. Realmente uma sociedade que tem funcionado, às vezes com resultados melhores. Acho que o Rei Davi é um dos melhores resultados dos dois. Talvez, Salomônicas, agora com a nova visão que estamos dando, possa chegar a esse ponto, mas Rei Davi foi um ápice para mim, ali encontramos, realmente, uma fórmula entre o que foi transpor o teatro grego a nossos dias e transformá-lo num musical de hoje ${ }^{8}$.

MARIANA Que é uma coisa que você tem procurado ao longo do seu trabalho, sempre esse diálogo né?

HUGO Para mim é absolutamente necessário. Sou aquele que prefere incomodar a entreter, fazer o outro pensar, no que está acontecendo com tudo. Estamos vivendo um momento muito interessante, com uma juventude que está lutando muito pelo espaço dela, pelo seu lugar mesmo, mas a gente tem que ter um cuidado gigantesco, por que essa fé, esse fundamentalismo religioso, esse conservadorismo que está embalando o mundo é perigosíssimo, quase fascista e teremos que lutar muito para não permitir que tirem de nós todos os direitos conquistados, por que aqui a pouco não sei como vai ser... Você vai ter que ter um corte de cabelo determinado, uma veste determinada, uma conduta determinada por um conjunto de dinossauros que não se cansam de retroceder. Um perigo terrível — talvez seja a resposta por não termos sido honestos com nós mesmos, por termos tido representantes que ignoraram seus princípios e os de quem os escolheram. Isso fortificou a onda conservadora, essa incerteza, essa descrença nos ideais e nas pessoas. Em quem você votaria? (silêncio geral...) Esse não-saber é brutal. É absolutamente necessário voltar a ter uma atitude e enfrentar-se com toda a força que nos dá a liberdade conquistada.
5 N.E. Hugo se refere ao trabalho na disciplina Técnicas Experimentais em Artes Cênicas (TEAC), no primeiro semestre de 2017, na qual ele conduziu um processo de pesquisa e experimentação em formação de jovens intérpretes. Cada semestre este curso é oferecido, como parte de sua atividade como docente pesquisador associado à Universidade de Brasília.

6 N.E. Salomônicas fecha a trilogia de obras dramático-musicais que justapõem crítica política e a narrativa dos primieros reis bíblicos (Saul, David, Salomão). Salomônicas foi elaborado durnate o TEAC do segundo semestre de 2016. Agora, neste segundo semestre de 2017 temos sua remontagem e rediscussão conceptual e estética. V. materiais disponíveis na Revista Dramaturgias n. 4, $p$ 48-108, Link: http://periodicos.unb.br/ index.php/dramaturgias/issue/ view/1728/showToc. Além disso, v. o vídeo da primeira montagem de Salomônicas: https://www.youtube. com/watch? $v=-m X I G H j e Q n o$.

7 N.E. Hugo Rodas e Marcus Mota trabalharam juntos nas obras: Idades. Lola (2002), As Partes todas de um benefício (2003), Salada para três (2003), No Muro. Ópera Hip-Hop (2009), Rei David (2012), Sete Contra Tebas (2013), Salomônicas (2016).

8 N.E. Sobre o musical Rei David, v. dissertação de mestrado Abordagens de Processos Criativos: O teatro de Hugo Rodas Link: http://repositorio. unb.br/handle/10482/18414). Ainda sobre o processo criativo de Rei David, v. o artigo Dramaturgia musical e o laboratório de dramaturgia: o caso seminal de Rei David, Revista Dramaturgias n.1 (2016):235-267. Link: http://periodicos.unb.br/index.php/ dramaturgias/article/view/21906. E ver ainda a database desenvolvida por Alexandre Rangel sobre o espetáculo 
MARIANA Isso é interessante por que você falou muito sobre essa questão da verdade, do livre arbítrio e eu queria saber a sua percepção em relação à ética no trabalho do ator, por que no departamento eles até fizeram uma mesa para conversar sobre ética no trabalho. Então tem sido um tema presente no departamento. Qual seria a sua percepção sobre isso"?

HUCO Pinta depois, manda lavar... Volta a pintar, volta a lavar. Ética é uma palavra muito difícil. Ética para mim é chegar na hora para dar aula, ética para mim é que o aluno me respeite e eu respeite o aluno, ética para mim é manter essa relação de aprendizado e não de luta, por que eu não sou teu pai. Ética para mim é despertar o interesse no outro, e não mandar no outro, isso para mim é ética. Eu acho que protestar é um dever, é inato, inerente a você. O que eu sinto às vezes é que a falta de diálogo reforça os "personagens" que ocupamos iniciando uma discussão sem fim. Se eu sou quem eu sou é por que deixei entrar todas as influência que eu tive na minha vida e na minha educação, jamais disse não a nenhuma e acho que você aprende absolutamente de tudo com tudo. Estudar o outro, ter alunos que queiram tudo de mim, que me exijam ao máximo para retribuí-los com a minha experiência e tudo o que eu possa... Isso para mim é ética: saber dar e receber. Eu não dou aula para ensinar, dou para alimentar o outro e alimentar-me ao mesmo tempo, algo meio vampiresco, mas esta é a energia que me mantém vivo.

MARIANA Para quem está entrando agora na área você teria algum conselho especial?

HUGO Sim! Não acredite em ninguém e acredite em todos, não fique comigo, aprende o que tem que aprender comigo, aprende o que tem que aprender com o outro e mistura, faz uma grande "salada". Em arte, ninguém está certo, tem que saber fazer essa salada e tirar o seu dela, saber o que tem dentro de si para mostrar e dar. Não desacreditar em nada. Acreditar que um mais um são dois, mas também são três. Acreditar nisso para mim é quase sagrado.

MARIANA Obrigada, Hugo!

HUCO Obrigado você!
Rei David: http://www.quasecinema. org/david/

9 N.E. Mariana complementa a pergunta: [Hugo questiona o que foi discutido na mesa redonda, Mariana explica sobre a concepção discutida de que a ética vai até onde o respeito vai, e sobre a pichação não-autorizada que ocorreu nas dependências do departamento]. Referência a um ato de pichação/vandalismo ocorrido dentro do Departamento de Artes Cênicas. 